\title{
Medicare Prescription Drug Plan Formulary Restrictions After Postmarket FDA Black Box Warnings
}

\author{
Michael T. Solotke, BS; Joseph S. Ross, MD, MHS; Nilay D. Shah, PhD; \\ Pinar Karaca-Mandic, PhD; and Sanket S. Dhruva, MD, MHS
}

\begin{abstract}
BACKGROUND: The boxed warning (also known as "black box warning") is one of the FDA's strongest safety actions for pharmaceuticals. After the FDA issues black box warnings for drugs, prescribing changes have been inconsistent. Formulary management may provide an opportunity to restrict access to drugs with serious safety concerns.

OBJECTIVE: To examine Medicare prescription drug plan formulary changes after new FDA postmarket black box warnings and major updates to preexisting black box warnings.

METHODS: In this cohort study, we identified each drug that received a new FDA postmarket black box warning or a major update to a preexisting black box warning from January 2008 through June 2015 and examined its formulary coverage. The main outcome measure was the proportion of Medicare prescription drug plan formularies providing unrestrictive coverage immediately before the black box warning, at least 1 year after the warning and at least 2 years after the warning. Unrestrictive formulary coverage was defined as coverage of a drug without prior authorization or step-therapy requirements.

RESULTS: Of 101 new black box warnings and major updates to preexisting warnings affecting 68 unique drug formulations, the mean percentage of formularies providing unrestrictive coverage changed from $65.4 \%(95 \%$ $\mathrm{Cl}=59.6 \%-71.2 \%)$ prewarning; $62.6 \%(95 \% \mathrm{Cl}=56.3 \%-68.9 \%, P=0.04)$ at least 1 year postwarning; and $61.9 \%(95 \% \mathrm{Cl}=55.4 \%-68.5 \%, P=0.10)$ at least 2 years postwarning.

CONCLUSIONS: The mean percentage of Medicare prescription drug plan formularies providing unrestrictive coverage decreased modestly by approximately 3 percentage points after drugs received postmarket FDA black box warnings. Formulary restrictions may present an underused mechanism to reduce use of potentially unsafe medications.
\end{abstract}

J Manag Care Spec Pharm. 2019;25(11):1201-09

Copyright $\odot 2019$, Academy of Managed Care Pharmacy. All rights reserved.

\section{What is already known about this subject}

The boxed warning (also known as "black box warning") is one of the FDA's strongest safety actions for pharmaceuticals.

Prescribing changes after the FDA issues black box warnings for drugs have been inconsistent, and 1 reason may be that formularies do not restrict access to unsafe drugs.

\section{What this study adds}

The mean percentage of Medicare formularies providing unrestrictive coverage of drugs for which the FDA issued a black box warning changed from $65.4 \%$ before the black box warning to $62.6 \%$ 1 year after the warning and $61.9 \% 2$ years after the warning. Formulary restrictions may represent an important opportunity to promote safer access to drugs with FDA black box warnings.

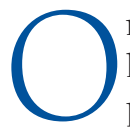
ne of the U.S. Food and Drug Administration's (FDA's) key tools to ensure drug safety is through updating product labeling with a boxed warning (also known as "black box warning" [BBW]), its strongest action short of a drug recall. ${ }^{1}$ BBWs alert prescribers to 1 of 3 situations: a potential adverse event serious enough that it must be considered when assessing the risks and benefits of prescribing a drug, a potential adverse event where appropriate use of a drug can minimize the likelihood or severity of the event, or a drug that was approved with restrictions to assure safe use. ${ }^{2}$

Despite the central role that BBWs play in supporting safe use of pharmaceuticals, the effect of these communications on prescribing has been inconsistent, ${ }^{3,4}$ and there has been varying adherence to BBW recommendations. ${ }^{5-7}$ Several reasons have been offered to explain this variation and lack of compliance with BBWs among prescribers, including awareness of BBWs, knowledge of how to translate BBW information into clinical practice, and agreement with the BBW's content. ${ }^{8-12}$ Additionally, although a BBW may designate a shift in the balance of benefits and risks for a drug, prescribers may ultimately decide that the drug still remains the best treatment option for specific patients.

Another factor that has received less attention but that affects the impact of BBWs on prescribing is insurer formulary coverage. A formulary lists the drugs covered by a plan, cost-sharing tiers, quantity limits, and associated utilization management strategies such as prior authorization or step therapy. Prior authorization requires a prescriber to receive approval before prescribing a drug and is intended to confirm that patients meet certain clinical criteria, whereas step therapy requires the use of another drug before a particular drug can be approved for reimbursement. ${ }^{13}$ Drugs excluded from a formulary are typically not reimbursed by the payer. ${ }^{14}$ 
Prior authorization, step therapy, and formulary exclusion can curtail prescribing of specific drugs with safety concerns. ${ }^{15-18}$ For example, after the rosiglitazone BBW update about increased myocardial ischemia risk, there was reduced rosiglitazone prescribing associated with Medicaid plans that implemented formulary restrictions compared with plans without formulary restrictions. ${ }^{4}$ More recently, the Centers for Medicare \& Medicaid Services (CMS) and many commercial insurers have implemented utilization management strategies to reduce opioid prescribing. ${ }^{19}$

CMS explicitly calls for formularies to consider drug safety, giving positive consideration to addition of utilization management tools to drugs that receive new BBWs and allowing unsafe drugs to be removed without requiring any standard advance notice requirements. ${ }^{20}$ Although formulary utilization management strategies are encouraged and can promote safer prescribing, studies examining individual drugs have shown that these strategies are used inconsistently after BBWs. After 9 drugs with safer available alternatives received postmarket BBWs for death and/or cardiovascular risk between 2007 and 2013, approximately half of Medicare prescription drug formularies restricted access to these drugs, but most continued to provide unrestrictive coverage. ${ }^{21}$ Similarly, there were minimal changes in Medicaid coverage of atypical antipsychotics and rosiglitazone after their 2005 and 2007 BBWs, respectively.,22 However, there has been no investigation of the effect of a consecutive, comprehensive set of BBWs on Medicare formulary restrictiveness, nor is there an understanding of the characteristics of BBWs that may be more frequently associated with utilization management.

To understand the effect of BBWs on formulary coverage and restrictiveness, we examined Medicare prescription drug formulary changes after all new postmarket BBWs and major updates to preexisting BBWs from January 2008 through June 2015. As Medicare provides prescription drug coverage for nearly 41 million people, ${ }^{23}$ our analysis has implications for a large number of patients and can inform a broader understanding of the effect of the FDA's key tools for supporting drug safety.

\section{Methods}

\section{Black Box Warnings}

To identify drugs available on the U.S. market for which the FDA issued either a new postmarket BBW or a major update to a preexisting BBW, we used multiple sources. First, we compiled all new BBWs and BBW updates issued from January 2008 through June 2015 using the FDA's MedWatch website (the FDA's drug safety information and adverse event reporting program),${ }^{24}$ all FDA Drug Safety Communications during this period, ${ }^{25}$ and relevant literature on BBWs. ${ }^{26-28}$ We then identified the most recent prescribing information before each BBW and the prescribing information associated with the BBW. Prescribing information contains the "essential scientific information needed for the safe and effective use of the drug' and is also known as professional labeling or drug labeling. ${ }^{29}$

Our study sample included all formulations affected by the BBW, as specified in the BBW source. If a BBW applied to multiple formulations of a drug, we treated each formulation separately because BBWs may differ between formulations of the same active pharmaceutical ingredient (API). Drugs containing the same API but with different brand names were considered separate BBWs, as these drugs often have distinct clinical and formulary management patterns. When a drug was available in a bioequivalent branded and generic form, we included only the generic form because generics are used significantly more often.

\section{BBW Data Extraction, Content Evaluation, and Explanatory Variables}

To detect all BBW changes, we compared the full BBW text in the prescribing information associated with the new or updated BBW with the BBW text in the most recent prescribing information available before the BBW (Appendix A, available in online article). BBW information was collected by 1 author, and any uncertainty was reviewed by at least 1 additional author. We identified whether the BBW was the first BBW for the drug or a major update to a preexisting BBW; we included both of these in our study because these warnings have the greatest relevance to clinical practice. Major updates were changes that would be expected to affect the clinical use of the drug, including addition of a new risk, information about risks in a new subpopulation or for a specific indication, important practicealtering clinical trial data, or addition of a Risk Evaluation \& Mitigation Strategy (REMS) program involving Elements To Assure Safe Use (ETASU). All other BBW updates were deemed minor and were excluded from our analysis.

We then characterized the new or updated BBW information according to a predefined set of BBW-specific and drugspecific variables, as previously described.$^{28}$ The BBW-specific features were relevant patient population (general indicated population, specific subpopulation, general indicated population with higher risk in specific subpopulation); inclusion in a class warning (yes, no); and presence of ETASU REMS (yes, no). ETASU REMS are risk management plans for which FDA mandates specific actions that clinicians must take to prescribe a drug. ${ }^{30}$

The drug-specific features that we characterized were drug class (small molecule pharmaceutical, biologic); availability of a bioequivalent generic (yes, no); formulation (oral tablet/ capsule; oral solution; subcutaneous injection; intravenous infusion; intramuscular injection, transdermal, inhaled); inclusion in a combination product with multiple APIs (combination product, single API); availability of alternatives for the primary FDA-approved indications without a BBW (no alternatives available, at least 1 alternative available without BBW, 
alternatives available but all have BBW); expected duration of use (acute [less than 1 month], intermediate [1-24 months], chronic [more than 24 months]); World Health Organization Anatomical Therapeutic Chemical (ATC) class (alimentary tract and metabolism, cardiovascular system, genitourinary system and sex hormones, anti-infectives for systemic use, antineoplastic and immunomodulating agents, nervous system, other); and inclusion in a CMS protected class (yes, no). CMS protected classes are 6 drug categories for which Medicare prescription drug plan formularies must cover "all or substantially all" drugs. ${ }^{20}$

\section{Study Drugs}

To identify BBWs for drugs that would be expected to have Medicare prescription drug plan formulary coverage, we excluded BBWs affecting drugs used only in an inpatient setting (because these are expected to be covered primarily by Medicare Part B), BBWs affecting nontherapeutics such as contrast agents, BBWs related to pregnancy risks (as the Medicare population's age demographics mean pregnancy risk is not a consideration for the vast majority of Medicare beneficiaries), and BBWs primarily affecting a pediatric indication or where the ultimate health effect of the risk in the BBW was in a pediatric population. We also excluded drugs if either prescribing information or formulary information was not available both before and after the BBW or if bioequivalent generics became available within 2 years after the BBW was issued (because generic introduction is a primary driver of formulary utilization management strategies).

\section{Selection of Controls}

Controls were selected from classes other than the BBW drug's class to avoid characterizing formulary coverage changes to within-class alternative therapies as a result of the BBW; we expected that some alternative within-class therapies may become concurrently less restricted if considered safer than the BBW drug, and we wanted to prevent such changes from confounding the results. Classes were defined using categories from the U.S. Pharmacopeia Convention Medicare Model Guidelines (Categories \& Classes) versions 5.0, 6.0, and 7.0. ${ }^{31}$ Drugs receiving BBWs during or before our study period were not used as controls.

One author identified controls for each drug receiving a BBW using a prespecified process; controls were verified by 3 other authors. Each control drug was required to match a BBW drug on the following variables: (a) brand or generic, (b) small molecule or biologic, (c) inclusion in a CMS protected class, and (d) formulation. Given the limited number of FDAapproved drugs, these matching variables were selected to control for factors that are expected to most significantly affect formulary coverage and restrictions.

\begin{tabular}{|c|c|}
\hline $\begin{array}{l}\text { TABLE 1 Characteristics of } 101 \text { FDA BI } \\
\text { Warnings Issued Between Ja } \\
\text { and June } 2015\end{array}$ & $\begin{array}{l}\text { Box } \\
\text { uary } 2008\end{array}$ \\
\hline Black Box Warning Characteristics & $\begin{array}{l}\text { Black Box } \\
\text { Warnings } \\
\mathrm{N}=101^{\mathrm{a}} \\
\mathrm{n}(\%)\end{array}$ \\
\hline \multicolumn{2}{|l|}{ Classification } \\
\hline New BBW & $35(35)$ \\
\hline Major update to preexisting BBW & $66(65)$ \\
\hline \multicolumn{2}{|l|}{ Patient population affected } \\
\hline General & $42(42)$ \\
\hline Specific population & $30(30)$ \\
\hline General population with higher risk in specific population & $29(29)$ \\
\hline Class warning & $47(47)$ \\
\hline \multicolumn{2}{|l|}{ REMS } \\
\hline $\begin{array}{l}\text { BBW accompanied by ETASU REMS or ETASU REMS } \\
\text { already in place }\end{array}$ & 17 (17) \\
\hline No ETASU REMS before or in association with BBW & $84(83)$ \\
\hline \multicolumn{2}{|c|}{$\begin{array}{l}\text { a Sums of percentages may not equal } 100 \% \text { due to rounding. } \\
\text { BBW=black box warning; ETASU=Elements to Assure Safe Use; FDA=U.S. Food } \\
\text { and Drug Administration; REMS = Risk Evaluation and Mitigation Strategies. }\end{array}$} \\
\hline
\end{tabular}

To avoid oversampling any individual control drug, each control API was matched to only 1 BBW API. Identical control drugs were used for BBW combination drugs containing the same API included in a BBW. For BBWs issued to multiple formulations of the same API, we used different controls for each formulation category. For drugs receiving a postmarket BBW at multiple time points, we used the same controls across the different time points. Appendix B (available in online article) includes a complete list of all study drugs and their matched controls.

\section{Medicare Prescription Drug Plan Formulary Data}

To obtain information on Medicare prescription drug plan formulary coverage and restrictiveness, we used data from the CMS Prescription Drug Formulary Files. These files contain formulary data for all stand-alone Prescription Drug Plans and Medicare Advantage Prescription Drug Plans.

\section{Outcome Variables}

Our primary outcome was the proportion of formularies providing unrestrictive coverage for each drug at 3 time points: immediately pre-BBW, at least 1 year post-BBW and at least 2 years post-BBW. We assessed formulary coverage and restrictions of the lowest available dose of each BBW drug formulation. We defined a formulary as unrestrictive if it covered the drug and did not require prior authorization or step therapy; a formulary providing coverage but requiring prior authorization and/or step therapy was defined as restrictive. Formulary exclusion was defined as a formulary that did not provide coverage of the drug. We did not include tiering, which 


\section{FIGURE 1 Flow Diagram of Black Box Warnings Issued Between January 2008 and June 2015 and} Drug Formulations for Which They Were Issued

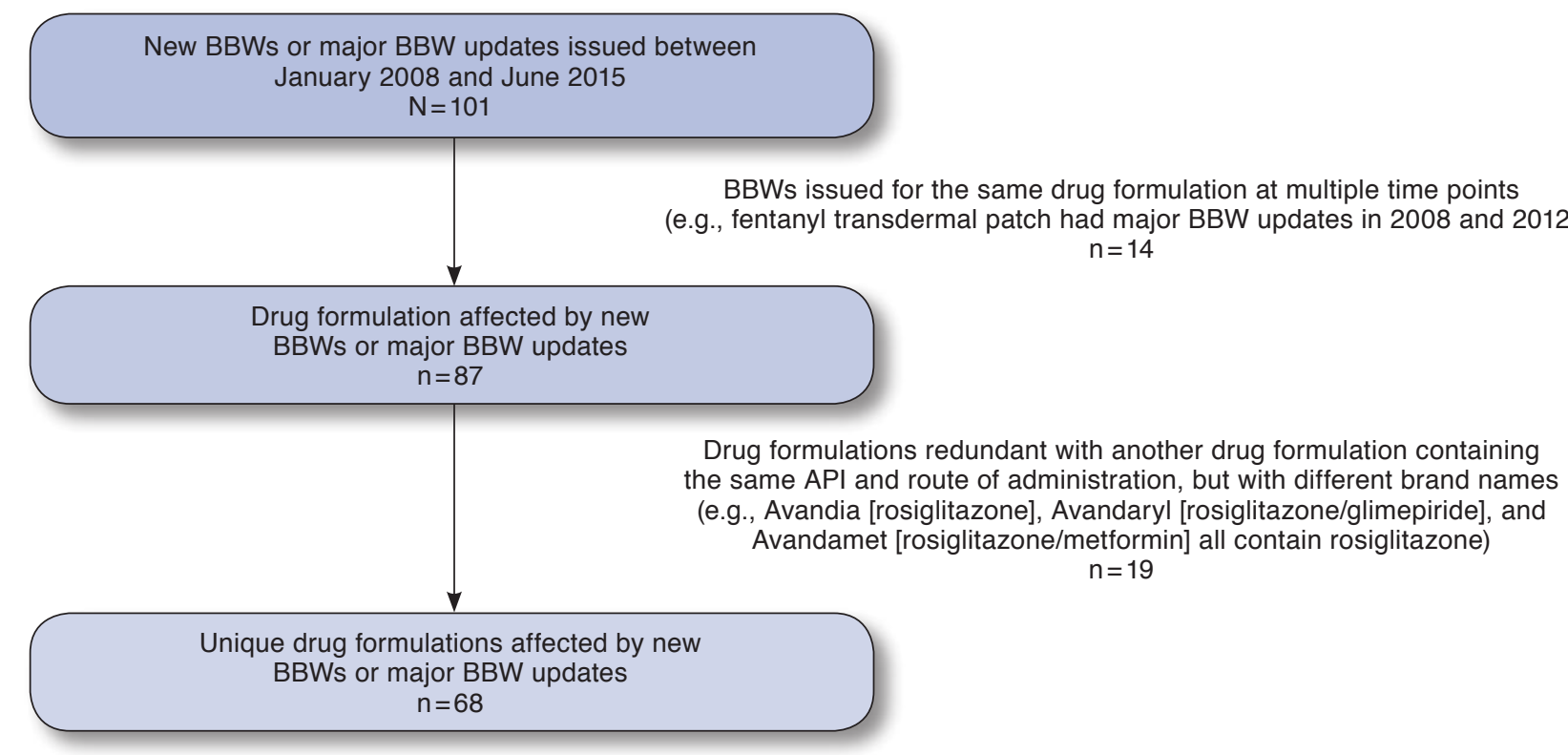

API = active pharmaceutical ingredient; $B B W=$ black box warning.

determines beneficiary cost-sharing, in our assessment of formulary restrictiveness because tiering is primarily employed by insurance plans to incentivize the use of lower cost or more cost-effective medications and is not used to restrict access to unsafe medications. ${ }^{32}$

\section{Statistical Analysis}

We first conducted descriptive analyses to characterize the BBWs, the drugs for which they were issued, and the control drugs. We calculated formulary restrictiveness for each BBW and control drug at all 3 time points, classifying the proportion of formularies providing unrestrictive coverage. Formularies that used formulary exclusion were included in the analysis. We analyzed each drug separately. If a plan formulary covered 1 of the study drugs without restrictions, we did not consider that formulary to be unrestrictive for all drugs; rather, it only factored into the calculation of the percentage of plans providing unrestrictive coverage of that particular drug. Our primary outcome was the mean of this value, i.e., the mean proportion of plan formularies providing unrestrictive formulary coverage for each drug at each of the 3 time points. Wilcoxon matchedpairs signed-ranks tests were performed to compare pre- and post-BBW formulary restrictiveness within the BBW drug sample and within the control drug sample.

Next, we used difference-in-differences regression analysis to compare pre-BBW to post-BBW changes in formulary restrictiveness between the BBW drugs and control drugs. We estimated a multivariable regression model relating the percentage of formularies providing unrestrictive coverage with an interaction term between the time period and an indicator for BBW or control drug. Two distinct models were estimated: 1 model compared formulary restrictiveness pre-BBW with formulary restrictiveness at least 1 year post-BBW, and the second model compared formulary restrictiveness pre-BBW with formulary restrictiveness at least 2 years post-BBW. The following characteristics were included as covariates in our adjusted models: inclusion in a combination product with multiple APIs, availability of alternatives, expected duration of use, and therapeutic area.

To examine the potential effect of BBW characteristics on formulary restrictiveness changes, we conducted exploratory subgroup difference-in-differences regression analyses for the following BBW characteristics: BBW classification, relevant patient population, inclusion in a class warning, presence of ETASU REMS.

We used Stata version 15 (StataCorp, College Station, TX) to conduct all analyses. We used an alpha of 0.05 for all statistical tests; we did not account for multiple comparisons. Because this project used publicly available data that did not involve human subjects, it was exempt from review by the Yale Human Research Protection Program. 


\section{Results}

\section{Characteristics of BBWs and Drugs for Which They Were Issued}

Between January 2008 and June 2015, 101 new BBWs and BBW updates met our inclusion criteria. Table 1 summarizes the characteristics of the 101 BBWs in our study. Approximately one third ( $\mathrm{n}=35,35 \%)$ were new BBWs, while two thirds $(n=66,65 \%)$ were major updates to preexisting BBWs. The BBW applied to the general population for 42 (42\%), a specific population for 30 (30\%), and the general indicated population with a higher risk in a specific population for the remaining 29 (29\%). Nearly half ( $n=47,47 \%)$ of BBWs applied to an entire drug class, and 17 (17\%) were accompanied by a new ETASU REMS or already had an ETASU REMS in place before the BBW.

Fourteen of these BBWs (14\%) were issued for the same drug formulation at multiple time points, yielding a total of $87 \mathrm{drug}$ formulations affected by BBWs (Figure 1). Of these drug formulations, 19 (22\%) were redundant with another drug formulation containing the same API and route of administration but with different brand names. The 101 BBWs therefore affected 68 unique drug formulations.

Of these 68 unique drug formulations that received BBWs, 64 (95\%) were small molecule pharmaceuticals, 17 (25\%) were included in a CMS protected class, 22 (32\%) were available in generic form, and 45 (66\%) were oral tablets or capsules (Table 2). For 38 (56\%), there were FDA-approved alternatives without a BBW for the primary indication available. Expected duration of use was greater than 24 months for 37 (54\%) of these formulations, and the most common therapeutic areas were anti-infectives for systemic use $(n=19,28 \%)$ and nervous system drugs $(n=19,28 \%)$.

\section{Formulary Restrictiveness of BBW Drugs}

The mean number of formularies analyzed annually was 325 . For drugs that received new or major updates to preexisting BBWs, the mean proportion of formularies providing unrestrictive coverage was $65.4 \%$ (95\% confidence interval $[\mathrm{CI}]=59.6 \%$ $71.2 \%)$ pre-BBW, $62.6 \%(95 \% \mathrm{CI}=56.3 \%-68.9 \%)$ at 1 year post-BBW $(P=0.04)$, and $61.9 \%(95 \% \mathrm{CI}=55.4 \%-68.5 \%)$ at 2 years post-BBW compared with pre-BBW (Table 3, $P=0.10$ ).

\section{Analysis Using Control Drugs}

Controls were selected for each drug formulation affected by a BBW (Table 2). Of the 68 control drugs, 61 (90\%) matched the BBW drug on all 4 matching variables, while 7 BBW-control drug pairs differed on 1 variable ( 6 on formulation and 1 on CMS protected class status). The mean proportion of formularies providing unrestrictive coverage for control drugs was not significantly changed from $65.9 \%(95 \% \mathrm{CI}=60.6 \%-71.3 \%)$ to $66.2 \%(95 \% \mathrm{CI}=60.5 \%-71.9 \%) 1$ year later $(P=0.45)$ and $67.1 \%$ (95\% CI $=61.4 \%-72.8 \%) 2$ years later compared with pre-BBW $(P=0.28)$

\begin{tabular}{|c|c|c|c|}
\hline $\begin{array}{l}\text { rug Formulation } \\
\text { haracteristics }\end{array}$ & $\begin{array}{c}\text { Black Box } \\
\text { Warning } \\
\text { Drugs } \\
\mathrm{n}=68 \\
\mathrm{n}(\%)^{\mathrm{a}}\end{array}$ & $\begin{array}{c}\text { Control } \\
\text { Drugs } \\
\mathrm{n}=68 \\
\mathrm{n}(\%)^{\mathrm{a}}\end{array}$ & $P$ Value \\
\hline lass & & & 1.000 \\
\hline Small molecule pharmaceutical & $64 \quad(94)$ & $64 \quad(94)$ & \\
\hline Biologic & $4 \quad(6)$ & $4 \quad(6)$ & \\
\hline $\begin{array}{l}\text { nclusion in CMS protected } \\
\text { lass }\end{array}$ & $17 \quad(25)$ & $16 \quad(24)$ & 0.861 \\
\hline Ivailability of generic & $22 \quad(32)$ & $22 \quad(32)$ & 1.000 \\
\hline ormulation & & & 0.022 \\
\hline Oral tablet/capsule & $45 \quad(66)$ & $46 \quad(68)$ & \\
\hline Oral solution & $6 \quad(9)$ & $5 \quad(7)$ & \\
\hline Subcutaneous injection & $\begin{array}{ll}1 & (1) \\
\end{array}$ & $6 \quad(9)$ & \\
\hline Intravenous infusion & $5 \quad(7)$ & $5 \quad(7)$ & \\
\hline Intramuscular injection & $2 \quad(3)$ & $1 \quad(1)$ & \\
\hline Transdermal & $\begin{array}{ll}6 & (9) \\
\end{array}$ & $5 \quad(7)$ & \\
\hline Inhaled & $3 \quad(4)$ & $0 \quad(0)$ & \\
\hline ombination product & $5 \quad(7)$ & $1 \quad(1)$ & $<0.001$ \\
\hline liternatives & & & $<0.001$ \\
\hline No alternatives available & $3 \quad(4)$ & $5 \quad(7)$ & \\
\hline $\begin{array}{l}\text { Alternatives available, at least } \\
1 \text { without BBW }\end{array}$ & $38 \quad(56)$ & $61(90)$ & \\
\hline $\begin{array}{l}\text { Alternatives available but all } \\
\text { have BBW }\end{array}$ & $27 \quad(40)$ & $2 \quad(3)$ & \\
\hline xpected duration of use & & & 0.287 \\
\hline Acute $(<1$ month $)$ & $15 \quad(22)$ & $16 \quad(24)$ & \\
\hline Intermediate (1-24 months) & $16 \quad(24)$ & $5 \quad(7)$ & \\
\hline Chronic (>24 months) & $37 \quad(54)$ & $47 \quad(69)$ & \\
\hline herapeutic class (ATC) & & & $<0.001$ \\
\hline $\begin{array}{l}\text { A: Alimentary tract and } \\
\text { metabolism }\end{array}$ & $3 \quad(4)$ & $14 \quad(21)$ & \\
\hline C: Cardiovascular system & $1 \quad(1)$ & $9 \quad(13)$ & \\
\hline J: Anti-infectives for systemic use & $19 \quad(28)$ & 12 (18) & \\
\hline $\begin{array}{l}\text { L: Antineoplastic and } \\
\text { immunomodulating agents }\end{array}$ & $10 \quad(15)$ & $8 \quad(12)$ & \\
\hline N: Nervous system & 19 (28) & 13 (19) & \\
\hline Other & 16 (24) & 12 (18) & \\
\hline
\end{tabular}

aSums of percentages may not equal $100 \%$ due to rounding.

$A T C=$ anatomical therapeutic chemical; $B B W=$ black box warning; $C M S=$ Centers for Medicare \& Medicaid Services; FDA =U.S. Food and Drug Administration.

In the unadjusted difference-in-differences model including drugs that received BBWs and their matched controls, a new or major update to a preexisting BBW was not associated with a significant change in formulary restrictiveness at 1 year post-BBW $(-3.1 \%, 95 \% \mathrm{CI}=-14.6 \%-8.4 \%)$ or 2 years post-BBW compared with pre-BBW $(-4.6 \%, 95 \% \mathrm{CI}=-16.3 \%-7.0 \%)$. Similarly, in the adjusted model, a new or major update to a preexisting BBW was not associated with a significant change in formulary restrictiveness at 1 year post-BBW $(-3.1 \%, 95 \% \mathrm{CI}=-13.5 \%-7.3 \%)$ 
TABLE 3 Association Between Formulary Changes and Black Box Warning Status in Uncontrolled and in Difference-in-Differences Analyses

\begin{tabular}{|c|c|c|c|c|c|c|c|}
\hline & \multirow{2}{*}{\begin{tabular}{|c} 
Pre-BBW Formulary \\
Restrictiveness
\end{tabular}} & \multicolumn{3}{|c|}{1 Year After BBW } & \multicolumn{3}{|c|}{2 Years After BBW } \\
\hline & & $\begin{array}{l}\text { Mean \% of } \\
\text { Formularies } \\
\text { Providing } \\
\text { Unrestrictive } \\
\text { Coverage }\end{array}$ & $\begin{array}{c}\text { Difference in } \\
\text { Differences } \\
(95 \% \text { CI }), \%\end{array}$ & $P$ Value & $\begin{array}{l}\text { Mean \% of } \\
\text { Formularies } \\
\text { Providing } \\
\text { Unrestrictive } \\
\text { Coverage }\end{array}$ & $\begin{array}{c}\text { Difference in } \\
\text { Differences } \\
(95 \% \mathrm{CI}), \%\end{array}$ & $P$ Value \\
\hline \multicolumn{8}{|c|}{ All BBWs $(\mathrm{N}=101)$ : unadjusted analysis, without controls } \\
\hline BBW drugs & \begin{tabular}{|l|l|}
65.4 \\
\end{tabular} & 62.6 & N/A & 0.04 & 61.9 & N/A & 0.10 \\
\hline \multicolumn{8}{|c|}{ All BBWs $(\mathrm{N}=101)$ : unadjusted difference-in-differences analysis } \\
\hline BBW drugs & 65.4 & 62.6 & \multirow{2}{*}{$-3.1 \quad(-14.6-8.4)$} & \multirow{2}{*}{$0.60^{\mathrm{a}}$} & 61.9 & \multirow{2}{*}{$-4.6 \quad(-16.3-7.0)$} & \multirow{2}{*}{$0.44^{b}$} \\
\hline Control drugs & 65.9 & 66.2 & & & 67.1 & & \\
\hline \multicolumn{8}{|c|}{ All BBWs $(\mathrm{N}=101)$ : adjusted difference-in-differences analysis ${ }^{c}$} \\
\hline BBW drugs & \begin{tabular}{|r|}
65.4 \\
\end{tabular} & 62.6 & \multirow{2}{*}{$-3.1 \quad(-13.5-7.3)$} & \multirow{2}{*}{$0.56^{\mathrm{a}}$} & 61.9 & \multirow{2}{*}{$-4.6 \quad(-15.2-5.9)$} & \multirow{2}{*}{$0.39 b$} \\
\hline Control drugs & \begin{tabular}{|r|r}
65.9 \\
\end{tabular} & 66.2 & & & 67.1 & & \\
\hline \multicolumn{8}{|c|}{$\begin{array}{l}\text { aP value represents difference-in-differences analysis of } 1 \text { year after BBW versus before BBW, measuring change in mean proportion of formularies providing unrestrictive } \\
\text { coverage for BBW drugs compared with control drugs. } \\
\text { bP value represents difference-in-differences analysis of } 2 \text { years after BBW versus before BBW, measuring change in mean proportion of formularies providing unrestrictive } \\
\text { coverage for BBW drugs compared with control drugs. }\end{array}$} \\
\hline
\end{tabular}

or 2 years post-BBW compared with pre-BBW $(-4.6 \%, 95 \%$ $\mathrm{CI}=-15.2 \%-5.9 \%)$.

\section{Exploratory Subgroup Analyses}

In exploratory subgroup analyses examining the effect of BBW characteristics on formulary coverage, there were no statistically significant changes in formulary restrictiveness when stratified by BBW classification, patient population affected, class warning status, or association with ETASU REMS (Table 4).

\section{Discussion}

In this comprehensive matched cohort analysis of every new BBW and major update to preexisting BBWs issued between January 2008 and June 2015 for drugs available on the U.S. market, the mean proportion of Medicare prescription drug formularies providing unrestrictive coverage decreased modestly, by approximately 3 percentage points, after drugs received postmarket FDA black box warnings, from 65.4\% pre-BBW, $62.6 \% 1$ year after the BBW and $61.9 \% 2$ years after the BBW. Our observation that Medicare formularies continued to provide unrestrictive access to drugs with serious known safety issues, even when safer alternatives were often available, indicates that pharmacy and therapeutic (P\&T) committees are sometimes not requiring the use of prior authorizations or step therapy, which may lead to greater vigilance in prescribing. Although the benefits of using a drug may still outweigh the risks in spite of a BBW, tools such as prior authorization or step therapy can help ensure that patients meet appropriate criteria to receive a drug and/or that safer alternatives have been trialed or considered..$^{13,14}$

Our analysis extends earlier research showing that inconsistent Medicare prescription drug formulary changes after BBWs for death and/or cardiovascular risk were issued for 9 oral drugs with safer available alternatives. ${ }^{21}$ Similarly, our findings are consistent with 2 studies that observed minimal changes to Medicaid formularies after single BBWs., ${ }^{4,22}$ Our study is more comprehensive and demonstrates that these findings are consistent regardless of a range of BBW and drug characteristics.

Safety communications, including BBWs, are critical tools for FDA to disseminate information about drug risks after regulatory approval. ${ }^{27,28,33}$ Approximately one third of novel therapeutics approved by FDA were affected by an FDA safety action after approval, which includes BBWs, ${ }^{27}$ and BBWs and other FDA safety communications have become increasingly common since passage of the Prescription Drug User Fee Act in 1992. ${ }^{34}$ Additionally, earlier research suggests that postmarket safety actions cannot be reliably predicted based on information available during preapproval review. ${ }^{35}$ Moreover, drugs are increasingly being approved under expedited pathways, which are associated with increased postapproval safety related label changes.$^{36}$ For all these reasons, payers must be more responsive to new safety information as it comes to light, adjusting formularies to promote patient and public health.

There are multiple possible explanations for the lack of increased formulary restrictiveness after BBWs. P\&T committees may place less emphasis on postapproval safety issues because they are tasked with incorporating an increasingly broad range 
TABLE 4 Association Between Formulary Changes and Black Box Warning Characteristics in Difference-in-Differences Exploratory Subgroup Analyses

\begin{tabular}{|c|c|c|c|c|}
\hline Black Box Warning Characteristics ${ }^{a}$ & $\begin{array}{c}1 \text { Year After BBW } \\
\text { Difference-in-Differences } \\
\text { Estimate, Adjusted } \\
\text { Analysis }(95 \% \mathrm{CI})^{\mathrm{b}}, \%\end{array}$ & $P$ Value ${ }^{c}$ & $\begin{array}{c}2 \text { Years After BBW } \\
\text { Difference-in-Differences } \\
\text { Estimate, Adjusted } \\
\text { Analysis }(95 \% \mathrm{CI})^{\mathrm{b}}, \%\end{array}$ & $P$ Value ${ }^{d}$ \\
\hline \multicolumn{5}{|l|}{ Classification } \\
\hline New BBW $(n=35)$ & $-0.63(-18.1-16.9)$ & 0.94 & $-2.4 \quad(-20.2-15.3)$ & 0.79 \\
\hline Major update to preexisting BBW $(\mathrm{n}=66)$ & $-4.3(-17.2-8.5)$ & 0.51 & $-5.8(-18.8-7.2)$ & 0.38 \\
\hline \multicolumn{5}{|l|}{ Patient population affected } \\
\hline General $(n=42)$ & $-5.4(-22.3-11.4)$ & 0.53 & $(-23.1-11.2)$ & 0.50 \\
\hline Specific population $(\mathrm{n}=30)$ & $-1.1 \quad(-19.5-17.2)$ & 0.90 & $(-21.9-15.8)$ & 0.75 \\
\hline General population with higher risk in specific population $(n=29)$ & $-1.6 \quad(-20.4-17.2)$ & 0.87 & $(-23.1-14.5)$ & 0.65 \\
\hline \multicolumn{5}{|l|}{ Class warning } \\
\hline Included in class warning $(n=47)$ & $-0.1 \quad(-15.6-15.3)$ & 0.99 & $-1.4 \quad(-16.8-14.0)$ & 0.86 \\
\hline Not included in class warning $(\mathrm{n}=54)$ & $-5.6(-19.8-8.5)$ & 0.44 & $-7.4 \quad(-22.0-7.1)$ & 0.32 \\
\hline \multicolumn{5}{|l|}{ REMS } \\
\hline $\begin{array}{l}\text { BBW accompanied by ETASU REMS or ETASU REMS already in place } \\
(\mathrm{n}=17)\end{array}$ & $-6.8 \quad(-33.1-19.4)$ & 0.61 & $-5.8 \quad(-32.4-20.8)$ & 0.67 \\
\hline No ETASU REMS before or in association with BBW $(\mathrm{n}=84)$ & $-2.3(-13.5-9.0)$ & 0.69 & $-4.4 \quad(-15.8-7.1)$ & 0.45 \\
\hline \multicolumn{5}{|c|}{$\begin{array}{l}\text { a Because each BBW drug was matched to a single control drug, the number of drugs in each group was identical. For example, in the new BBW analysis, there were } \\
35 \text { BBW drugs and } 35 \text { control drugs. } \\
\text { bCovariates used in adjusted analysis were expected duration of use, therapeutic class, inclusion in a combination product, and availability of alternatives. } \\
\text { cP value represents difference-in-differences analysis of } 1 \text { year after BBW versus before BBW, measuring change in mean proportion of formularies providing unrestrictive } \\
\text { coverage for BBW drugs compared with control drugs. } \\
\text { dP value represents difference-in-differences analysis of } 2 \text { years after BBW versus before BBW, measuring change in mean proportion of formularies providing unrestrictive } \\
\text { coverage for BBW drugs compared with control drugs. } \\
B B W=\text { black box warning; CI= confidence interval; ETASU = Elements to Assure Safe Use; REMS=Risk Evaluation and Mitigation Strategies. }\end{array}$} \\
\hline
\end{tabular}

of considerations in their formulary decisions, including quality, cost, access, ensuring availability of critical medicines, CMS requirements (including that all medication classes listed in the U.S. Pharmacopoeia Medicare Model Guidelines be included on the formulary and that "all or nearly all" drugs in 6 "protected" classes be included), changes in health system organization, and Affordable Care Act requirements. ${ }^{37}$ Payers may also consider the responsibility to ensure that patients have immediate access to critical medications such as antibiotics, limiting their ability to apply formulary management tools on an entire class. Additionally, P\&T committees may rely on other stakeholders to limit access to unsafe drugs. For example, they may expect FDA to withdraw drugs with serious safety issues or physicians to reduce prescribing. Finally, the administrative cost and burden associated with implementing prior authorization or step therapy requirements may factor into P\&T committee decisions not to use these tools after BBWs. The decision not to utilize formulary management tools after FDA's strongest safety action is surprising because half of BBWs are issued for risk of death and many BBWs are issued for commonly prescribed drugs such as antibiotics, estrogencontaining products, asthma/chronic obstructive pulmonary disease treatments, and analgesics. ${ }^{28}$
CMS instructs its contracting Part D sponsor formularies to consider drug safety and efficacy when making decisions about which drugs to include on formularies. ${ }^{20}$ According to Part D guidelines, Medicare P\&T committees must meet at least quarterly. Further, while formularies generally are constrained in changing once the coverage year begins, CMS specifically allows formularies to add utilization management tools at any time after a new FDA BBW and allows these drugs to be removed without meeting advance notice requirements. However, we found that even 2 years after new BBWs or major, clinically significant BBW updates, there were not significant changes to formulary coverage of BBW drugs. These findings suggest that despite several opportunities - including explicit guidance from CMS - to adjust restrictiveness of drugs in the 2 years after BBWs, formulary utilization management tools are not being used to promote safer prescribing. As a result, some patients may be unnecessarily exposed to drugs with serious safety risks.

\section{Limitations}

Our study should be considered in the context of several possible limitations. We analyzed only Medicare formularies, so our findings may not be generalizable to other payer formularies. However, since Medicare is the largest payer in the United States, our findings apply to a large segment of the U.S. 
population. We also did not include safety edits applied at the point of sale or point of distribution (e.g., "soft edits") in our analysis because the CMS formulary files do not include this information. However, because these "soft edits" have primarily been applied to opioids and have largely been used after our study period, we did not expect them to affect our study findings, given the limited number of opioids in our sample. Our analysis also did not include quantity limits because we did not expect these restrictions to be used as primarily safety-related utilization management tools among drugs in our study.

Because each drug formulation has its own prescribing information and is listed separately on each formulary, we treated each formulation of a drug separately rather than grouping formulations together, in order to completely and accurately detect changes in formulary restrictiveness.

We recognize that in certain scenarios, prior authorizations and step therapy requirements are not applied at the formulation level. Further, while we used a robust process to select control drugs, these control drugs may not be completely analogous to the BBW drugs. Specifically, because of the limited number of possible control drugs on the U.S. market, we could not include other potential matching characteristics when selecting controls, such as number of years on the market, magnitude of drug's health benefit, and number of available alternatives.

There were differences between the BBW drugs and drugs selected for the control group in our analysis, such as therapeutic class and availability of alternatives without BBWs. However, we do not think that these differences affected our analysis because our findings were consistent for both the analysis focused only on the BBW drugs as well as the analysis comparing BBW and control drugs.

Finally, although we included all new and major updates to preexisting BBWs, the relatively small number of BBWs may have limited statistical power to detect significant changes in formulary restrictiveness.

\section{Conclusions}

The mean proportion of Medicare prescription drug plan formularies providing unrestrictive coverage (i.e., coverage without prior authorization requirements, step therapy requirements, or formulary exclusions) decreased modestly, by approximately 3 percentage points, after drugs received postmarket FDA black box warnings. These findings were consistent regardless of BBW or drug characteristics. Formulary restrictions after BBWs may represent an opportunity to promote safer prescribing.

\section{Authors}

MICHAEL T. SOLOTKE, BS, School of Medicine, Yale University, New Haven, Connecticut. JOSEPH S. ROSS, MD, MHS, National Clinician Scholars Program, Department of Internal Medicine, Yale University, New Haven, Connecticut; Section of General Internal Medicine, Department of Internal Medicine, Yale University, New Haven, Connecticut; Department of Health Policy and Management, Yale School of Public Health, New Haven, Connecticut; and Center for Outcomes Research and Evaluation, Yale-New Haven Hospital, New Haven, Connecticut. NILAY D. SHAH, PhD, Division of Health Care Policy and Research and Kern Center for the Science of Health Care Delivery, Mayo Clinic, Rochester, Minnesota; PINAR KARACA-MANDIC, PhD, Carlson School of Management, Department of Finance, University of Minnesota, Minneapolis; and SANKET S. DHRUVA, MD, MHS, Section of Cardiology, Department of Medicine, San Francisco Veterans Affairs Medical Center, and University of California, San Francisco, School of Medicine, San Francisco, California.

AUTHOR CORRESPONDENCE: Sanket S. Dhruva, MD, MHS, San Francisco Veterans Affairs Medical Center, 4150 Clement St., Bldg. 203, Rm. 2A-18, San Francisco, CA 94121. E-mail: Sanket.Dhruva@ucsf.edu.

\section{DISCLOSURES}

This study was supported by a student research grant received by Solotke and provided by the Yale School of Medicine Office of Student Research under National Institutes of Health training grant award T35DK104689. KaracaMandic, Shah, and Ross acknowledge support from Agency for Healthcare Research and Quality (AHRQ) grant R01 HS025164, which studies factors associated with de-adoption of drug therapies shown to be ineffective or unsafe. The content of this study is solely the responsibility of the authors and does not necessarily represent the official views of the National Institutes of Health. The authors assume full responsibility for the accuracy and completeness of the ideas presented.

Ross has received support from the following: the U.S. Food and Drug Administration (FDA) as part of the Centers for Excellence in Regulatory Science and Innovation (CERSI) program; Johnson and Johnson through Yale University to develop methods of clinical trial data sharing; Medtronic and the FDA to develop methods for postmarket surveillance of medical devices; the Blue Cross Blue Shield Association to better understand medical technology evaluation; the Centers for Medicare \& Medicaid Services (CMS) to develop and maintain performance measures that are used for public reporting; the AHRQ to examine community predictors of health care quality; and the Laura and John Arnold Foundation, which established the Collaboration for Research Integrity and Transparency at Yale University. Shah has received support from the FDA as part of the CERSI program. In addition, he has received support through the Mayo Clinic from CMS, AHRQ, National Science Foundation, and Patient-centered Outcomes Research Institute. Karaca-Mandic has provided consulting services to Precision Health Economics and Tactile Medical for work unrelated to this manuscript. Dhruva and Solotke have no conflicts of interest to report.

\section{REFERENCES}

1. U.S. Food and Drug Administration. What we do. March 2018. Available at: https://www.fda.gov/aboutfda/whatwedo/. Accessed October 4, 2019. 
2. U.S. Food and Drug Administration. Guidance for industry: warnings and precautions, contraindications, and boxed warning sections of labeling for human prescription drug and biological products-content and format. October 2011. Available at: https://www.fda.gov/downloads/drugs/guidances/ucm075096.pdf. Accessed October 4, 2019.

3. Dusetzina SB, Higashi AS, Dorsey ER, et al. Impact of FDA drug risk communications on health care utilization and health behaviors: a systematic review. Med. Care. 2012;50(6):466-78.

4. Ross JS, Jackevicius C, Krumholz HM, et al. State Medicaid programs did not make use of prior authorization to promote safer prescribing after rosiglitazone warning. Health Aff (Millwood). 2012;31(1):188-98.

5. Lasser KE, Seger DL, Yu DT, et al. Adherence to black box warnings for prescription medications in outpatients. Arch Intern Med. 2006;166(3):338-44.

6. Wagner AK, Chan KA, Dashevsky I, et al. FDA drug prescribing warnings: is the black box half empty or half full? Pharmacoepidemiol Drug Saf. 2006;15(6):369-86.

7. Shah ND, Montori VM, Krumholz HM, Tu K, Alexander GC, Jackevicius CA. Responding to an FDA warning: geographic variation in the use of rosiglitazone. N Engl J Med. 2010;363(22):2081-84.

8. Smollin CG, Fu J, Levin R. Recognition and knowledge of medications with black box warnings among pediatricians and emergency physicians. J Med Toxicol. 2016;12(2):180-84.

9. Masoudi FA, Wang Y, Inzucchi SE, et al. Metformin and thiazolidinedione use in Medicare patients with heart failure. JAMA. 2003;290(1):81-85.

10. Dorsey E, Rabbani A, Gallagher SA, Conti RM, Alexander G. Impact of FDA black box advisory on antipsychotic medication use. Arch Intern Med. 2010;170(1):96-103.

11. Lineberry TW, Bostwick JM, Beebe TJ, Decker PA. Impact of the FDA black box warning on physician antidepressant prescribing and practice patterns: opening Pandora's suicide box. Mayo Clin Proc. 2007;82(4):518-20.

12. Kornfield R, Watson S, Higashi AS, et al. Effects of FDA advisories on the pharmacologic treatment of ADHD, 2004-2008. Psychiatr Serv. 2013;64(4):339-46

13. Academy of Managed Care Pharmacy. Prior authorization. April 2012. Available at: http://www.amcp.org/prior_authorization/. Accessed October 4, 2019.

14. Academy of Managed Care Pharmacy. Formulary management. November 2009. Available at: http://www.amcp.org/WorkArea/ DownloadAsset.aspx?id=9298. Accessed October 4, 2019.

15. Starner CI, Fenrick B, Coleman J, Wickersham P, Gleason PP Rosiglitazone prior authorization safety policy: a cohort study. J Manag Care Pharm. 2012;18(3):225-33. Available at: https://www.jmcp.org/doi/10.18553/ jmcp.2012.18.3.225.

16. Fischer MA, Schneeweiss S, Avorn J, Solomon DH. Medicaid priorauthorization programs and the use of cyclooxygenase-2 inhibitors. N Engl J Med. 2004;351(21):2187-94.

17. Fischer MA, Choudhry NK, Winkelmayer WC. Impact of Medicaid prior authorization on angiotensin-receptor blockers: can policy promote rational prescribing? Health Aff (Millwood). 2007;26(3):800-07.

18. Fischer MA, Avorn J. Step therapy—clinical algorithms, legislation, and optimal prescribing. JAMA. 2017;317(8):801-02.

19. Haegerich TM, Paulozzi LJ, Manns BJ, Jones CM. What we know, and don't know, about the impact of state policy and systems-level interventions on prescription drug overdose. Drug Alcohol Depend. 2014;(145):34-47.
20. Centers for Medicare $\&$ Medicaid Services. Medicare prescription drug benefit manual. chapter 6-Part D drugs and formulary requirements. January 2016. Available at: https://www.cms.gov/Medicare/PrescriptionDrug-Coverage/PrescriptionDrugCovContra/Downloads/Part-D-BenefitsManual-Chapter-6.pdf. Accessed October 4, 2019.

21. Dhruva SS, Karaca-Mandic P, Shah ND, Shaw DL, Ross JS. Association between FDA black box warnings and Medicare formulary coverage changes. Am J Manag Care. 2017;23(9):e310-15.

22. Polinski JM, Wang PS, Fischer MA. Medicaid's prior authorization program and access to atypical antipsychotic medications. Health Aff (Millwood). 2007;26(3):750-60

23. Kaiser Family Foundation. Medicare Part D in 2016 and trends over time. September 2016. Available at: https://www.kff.org/medicare/report/ medicare-part-d-in-2016-and-trends-over-time/. Accessed October 4, 2019.

24. U.S. Food \& Drug Administration. MedWatch: the FDA Safety Information and Adverse Event Reporting Program. June 19, 2019. Available at: https://www.fda.gov/Safety/MedWatch/default.htm. Accessed October 4, 2019.

25. U.S. Food \& Drug Administration. Drug safety communications. Available at: https://www.fda.gov/Drugs/DrugSafety/ucm199082.htm Accessed September 13, 2019.

26. Winterfield L, Vleugels RA, Park KK. The value of the black box warning in dermatology. J Drugs Dermatol. 2015;14(7):660-66.

27. Downing NS, Shah ND, Aminawung JA, et al. Postmarket safety events among novel therapeutics approved by the US Food and Drug Administration between 2001 and 2010. JAMA. 2017;317(18):1854-63.

28. Solotke MT, Dhruva SS, Downing NS, Shah ND, Ross JS. New and incremental FDA black box warnings from 2008 to 2015. Expert Opin Drug Saf. 2018;17(2):117-23.

29. Code of Federal Regulations. Title 21—food and drugs. April 1, 2018. Available at: https://www.accessdata.fda.gov/scripts/cdrh/cfdocs/cfffr/ CFRSearch.cfm. Accessed October 4, 2019.

30. U.S. Food \& Drug Administration. REMS@FDA: approved risk evaluation and mitigation strategies (REMS). 2019. Available at: https://www. accessdata.fda.gov/scripts/cder/rems/. Accessed October 4, 2019.

31. U.S. Pharmacopeia. USP Medicare model guidelines. July 22, 2019. Available at: http://www.usp.org/health-quality-safety/usp-medicare-modelguidelines. Accessed October 4, 2019.

32. Chernew ME, Rosen AB, Fendrick AM. Value-based insurance design. Health Aff (Millwood). 2007;26(2):w195-203.

33. Lester J, Neyarapally GA, Lipowski E, Graham CF, Hall M, Dal Pan G. Evaluation of FDA safety-related drug label changes in 2010. Pharmacoepidemiol Drug Saf. 2013;22(3):302-05.

34. Frank C, Himmelstein DU, Woolhandler S, et al. Era of faster FDA drug approval has also seen increased black-box warnings and market withdrawals. Health Aff (Millwood). 2014;33(8):1453-59.

35. Schick A, Miller KL, Lanthier M, Dal Pan G, Nardinelli C. Evaluation of pre-marketing factors to predict post-marketing boxed warnings and safety withdrawals. Drug Saf. 2017;40(6):497-503.

36. Mostaghim SR, Gagne JJ, Kesselheim AS. Safety related label changes for new drugs after approval in the US through expedited regulatory pathways: retrospective cohort study. BMJ. 2017;358:j3837.

37. Vogenberg FR, Marcoux R, Rumore MM. Systemic market and organizational changes: impact on P\&T committees. P T. 2017;42(1):28-32. 


\section{APPENDIX A Summary of Black Box Warnings}

\begin{tabular}{|c|c|c|}
\hline Active Pharmaceutical Ingredient Name & Year & Summary of BBW Content \\
\hline Abacavir (oral solution) & 2008 & Major update: hypersensitivity reactions \\
\hline $\begin{array}{l}\text { Abacavir (oral tablet, including abacavir/lamivudine and } \\
\text { abacavir/lamivudine/zidovudine) }\end{array}$ & 2008 & Major update: hypersensitivity reactions \\
\hline Acetaminophen (including 3 combination products) & 2011 & New BBW: hepatotoxicity \\
\hline Apixaban & 2014 & Major update: spinal/epidural hematoma \\
\hline Arformoterol & 2010 & Major update: asthma-related death \\
\hline Azathioprine & 2011 & Major update: malignancy \\
\hline Becaplermin & 2008 & New BBW: malignancy \\
\hline Bedaquiline & 2015 & Major update: QT prolongation \\
\hline Botulinum toxin & 2009 & New BBW: distant spread of toxin effect \\
\hline Buprenorphine & 2012 & Major update: respiratory depression, accidental exposure \\
\hline Bupropion (Wellbutrin XL, Aplenzin) & 2009 & Major update: neuropsychiatric events \\
\hline Bupropion (Wellbutrin, Wellbutrin Sustained Release) & 2009 & Major update: neuropsychiatric events \\
\hline Bupropion (Zyban) & 2009 & Major update: neuropsychiatric events \\
\hline Ciprofloxacin (intravenous) & $2008 / 2011$ & $\begin{array}{l}\text { New BBW: tendonitis and tendon rupture (2008). Major update: myasthenia } \\
\text { gravis exacerbation (2011) }\end{array}$ \\
\hline Ciprofloxacin (oral solution) & $2008 / 2011$ & $\begin{array}{l}\text { New BBW: tendonitis and tendon rupture (2008). Major update: myasthenia } \\
\text { gravis exacerbation (2011) }\end{array}$ \\
\hline Ciprofloxacin (oral tablet) & $2008 / 2011$ & $\begin{array}{l}\text { New BBW: tendonitis and tendon rupture (2008). Major update: myasthenia } \\
\text { gravis exacerbation (2011) }\end{array}$ \\
\hline Clopidogrel & 2010 & New BBW: diminished effectiveness in poor metabolizers \\
\hline Conjugated estrogens & 2008 & Major update: endometrial cancer \\
\hline Dabigatran & $2013 / 2014$ & $\begin{array}{l}\text { New BBW: thrombotic events after discontinuation (2013). Major update: spi- } \\
\text { nal/epidural hematoma (2014) }\end{array}$ \\
\hline Dantrolene & 2012 & Major update: hepatotoxicity \\
\hline Deferasirox & $2010 / 2012$ & $\begin{array}{l}\text { New BBW: renal failure, hepatic failure, GI hemorrhage (2010). Major update: } \\
\text { renal failure, hepatic failure, GI hemorrhage (2012) }\end{array}$ \\
\hline Dronedarone & 2011 & Major update: stroke, heart failure \\
\hline $\begin{array}{l}\text { Estradiol (branded products: Evamist, Estring; } \\
\text { combination products: estradiol/norethindrone, } \\
\text { norelgestromin/ethinyl estradiol) }\end{array}$ & Multiple & Major update: endometrial cancer \\
\hline Estradiol (available as generic: Estraderm, Vivelle-Dot) & Multiple & Major update: endometrial cancer \\
\hline Etanercept & 2008 & New BBW: risk of infections \\
\hline Everolimus & 2012 & Major update: mortality in heart transplantation \\
\hline Ezogabine & 2013 & New BBW: retinal abnormalities, potential vision loss \\
\hline Fentanyl (oral tablet) & 2008 & Major update: appropriate patient selection, dosing, and substitution \\
\hline Fentanyl (oral transmucosal) & 2009 & Major update: appropriate patient selection, dosing, and substitution \\
\hline Fentanyl (transdermal) & $2008 / 2012$ & $\begin{array}{l}\text { Major update: application site safety (2008). } \\
\text { Major update: abuse potential, respiratory depression, accidental exposure } \\
\text { (2012) }\end{array}$ \\
\hline Formoterol (including formoterol, budesonide/formoterol) & 2010 & Major update: asthma-related death \\
\hline Gemifloxacin & $2008 / 2011$ & $\begin{array}{l}\text { New BBW: tendonitis and tendon rupture (2008). Major update: myasthenia } \\
\text { gravis exacerbation (2011) }\end{array}$ \\
\hline Hydromorphone & 2012 & Major update: respiratory depression, abuse potential \\
\hline Ketoconazole & 2013 & $\begin{array}{l}\text { Major update: use only when other effective antifungal therapy is not available } \\
\text { or tolerated }\end{array}$ \\
\hline Lapatinib & 2008 & New BBW: hepatotoxicity \\
\hline Leflunomide & 2010 & Major update: hepatotoxicity \\
\hline Lenalidomide & 2014 & Major update: venous and arterial thromboembolism \\
\hline Levofloxacin (intravenous) & $2008 / 2011$ & $\begin{array}{l}\text { New BBW: tendonitis and tendon rupture (2008). Major update: myasthenia } \\
\text { gravis exacerbation (2011) }\end{array}$ \\
\hline Levofloxacin (oral solution) & $2008 / 2011$ & $\begin{array}{l}\text { New BBW: tendonitis and tendon rupture (2008). Major update: myasthenia } \\
\text { gravis exacerbation (2011) }\end{array}$ \\
\hline Levofloxacin (oral tablet) & $2008 / 2011$ & $\begin{array}{l}\text { New BBW: tendonitis and tendon rupture (2008). Major update: myasthenia } \\
\text { gravis exacerbation (2011) }\end{array}$ \\
\hline Mefloquine & 2013 & New BBW: neuropsychiatric events \\
\hline
\end{tabular}




\section{APPENDIX A Summary of Black Box Warnings (continued)}

\begin{tabular}{|c|c|c|}
\hline Active Pharmaceutical Ingredient Name & Year & Summary of BBW Content \\
\hline Methadone (oral solution) & 2012 & Major update: respiratory depression, abuse potential, QT prolongation \\
\hline Methadone (oral tablet) & 2012 & Major update: abuse potential, QT prolongation, accidental exposure \\
\hline Metoclopramide (intramuscular) & 2009 & New BBW: tardive dyskinesia \\
\hline Metoclopramide (oral tablet) & 2009 & New BBW: tardive dyskinesia \\
\hline Morphine & 2012 & Major update: respiratory depression, abuse potential, accidental exposure \\
\hline Moxifloxacin (intravenous) & $2008 / 2011$ & $\begin{array}{l}\text { New BBW: tendonitis and tendon rupture (2008). Major update: myasthenia } \\
\text { gravis exacerbation (2011) }\end{array}$ \\
\hline Moxifloxacin (oral tablet) & $2008 / 2011$ & $\begin{array}{l}\text { New BBW: tendonitis and tendon rupture (2008). Major update: myasthenia } \\
\text { gravis exacerbation (2011) }\end{array}$ \\
\hline Nevirapine & 2010 & Major update: hepatotoxicity when used for PEP \\
\hline Norfloxacin & $2008 / 2011$ & $\begin{array}{l}\text { New BBW: tendonitis and tendon rupture (2008). Major update: myasthenia } \\
\text { gravis exacerbation (2011) }\end{array}$ \\
\hline Ofloxacin & $2008 / 2011$ & $\begin{array}{l}\text { New BBW: tendonitis and tendon rupture (2008). Major update: myasthenia } \\
\text { gravis exacerbation (2011) }\end{array}$ \\
\hline Oxycodone & 2012 & Major update: respiratory depression, accidental exposure \\
\hline Oxymorphone & 2012 & Major update: respiratory depression, abuse potential, accidental exposure \\
\hline Pomalidomide & 2015 & Major update: venous and arterial thromboembolism \\
\hline Propylthiouracil & 2010 & New BBW: hepatotoxicity \\
\hline Quetiapine & 2008 & Major update: suicidality and antidepressant drugs \\
\hline Quinine sulfate & 2009 & New BBW: hematologic reactions, renal impairment \\
\hline Rituximab & 2013 & Major update: hepatitis B vaccine reactivation \\
\hline $\begin{array}{l}\text { Rosiglitazone (including rosiglitazone, rosiglitazone/ } \\
\text { glimepiride, rosiglitazone/metformin) }\end{array}$ & 2011 & Major update: risk of myocardial infarction \\
\hline Salmeterol (including salmeterol, fluticasone/salmeterol) & 2010 & Major update: asthma-related death \\
\hline Sunitinib & 2010 & New BBW: hepatotoxicity \\
\hline Tapentadol & 2012 & Major update: respiratory depression, abuse potential, accidental exposure \\
\hline Telaprevir & 2012 & New BBW: serious skin reactions \\
\hline Tenofovir (including tenofovir/emtricitabine) & 2012 & Major update: HIV-negative confirmation for PrEP indication \\
\hline Thiothixene & 2008 & New BBW: mortality in elderly patients with dementia-related psychosis \\
\hline Tigecycline & 2013 & New BBW: all-cause mortality \\
\hline Toremifene & 2011 & New BBW: QT prolongation \\
\hline Varenicline & 2009 & New BBW: neuropsychiatric events \\
\hline
\end{tabular}




\section{APPENDIX B Black Box Warning Drugs and Controls}

\begin{tabular}{|c|c|c|c|c|c|}
\hline Active Pharmaceutical Ingredient Name & Control & $\begin{array}{l}\text { Brand vs. } \\
\text { Generic Match }\end{array}$ & $\begin{array}{l}\text { Small Molecule } \\
\text { vs. Biologic } \\
\text { Match }\end{array}$ & $\begin{array}{l}\text { CMS Protected } \\
\text { Class Match }\end{array}$ & $\begin{array}{l}\text { Formulation } \\
\text { Match }\end{array}$ \\
\hline Abacavir (oral solution) & Imatinib & $\times$ & $\times$ & $\times$ & \\
\hline $\begin{array}{l}\text { Abacavir (oral tablet, including abacavir/lamivudine and } \\
\text { abacavir/lamivudine/zidovudine) }\end{array}$ & Erlotinib & $\times$ & $\times$ & $x$ & $\times$ \\
\hline Acetaminophen (including 3 combination products) & Eplerenone & $x$ & $x$ & $x$ & $x$ \\
\hline Apixaban & Linagliptin & $\times$ & $\times$ & $x$ & $\times$ \\
\hline Arformoterol & Insulin detemir & $\times$ & $x$ & $x$ & \\
\hline Azathioprine & Topiramate & $\times$ & $\times$ & $x$ & $x$ \\
\hline Becaplermin & Abatacept & $\times$ & $x$ & $x$ & \\
\hline Bedaquiline & Sitagliptin & $\times$ & $\times$ & $\times$ & $x$ \\
\hline Botulinum toxin & Interferon beta-1B & $\times$ & $\times$ & $x$ & \\
\hline Buprenorphine & Rivastigmine & $\times$ & $\times$ & $x$ & $x$ \\
\hline Bupropion (Wellbutrin XL, Aplenzin) & Atazanavir & $\times$ & $\times$ & $x$ & $\times$ \\
\hline Bupropion (Wellbutrin, Wellbutrin Sustained Release) & Primidone & $\times$ & $\times$ & $x$ & $\times$ \\
\hline Bupropion (Zyban) & Frovatriptan & $x$ & $\times$ & $x$ & $x$ \\
\hline Ciprofloxacin (intravenous) & Ondansetron & $x$ & $x$ & $x$ & $x$ \\
\hline Ciprofloxacin (oral solution) & Oseltamivir & $x$ & $x$ & $x$ & $x$ \\
\hline Ciprofloxacin (oral tablet) & Pravastatin & $x$ & $x$ & $x$ & $x$ \\
\hline Clopidogrel & Acamprosate & $x$ & $x$ & $x$ & $x$ \\
\hline Conjugated estrogens & Tacrolimus & $\times$ & $x$ & $x$ & $x$ \\
\hline Dabigatran & Lubiprostone & $x$ & $x$ & $x$ & $x$ \\
\hline Dantrolene & Pantoprazole & $\times$ & $x$ & $x$ & $x$ \\
\hline Deferasirox & Tetrabenazine & $x$ & $x$ & $x$ & $x$ \\
\hline Dronedarone & Eletriptan & $x$ & $x$ & $x$ & $x$ \\
\hline $\begin{array}{l}\text { Estradiol (branded products: Evamist, Estring; } \\
\text { combination products: estradiol/norethindrone, } \\
\text { norelgestromin/ethinyl estradiol) }\end{array}$ & Retapamulin & $\times$ & $\times$ & $x$ & $x$ \\
\hline Estradiol (available as generic: Estraderm, Vivelle-Dot) & Lidocaine & $x$ & $\times$ & $x$ & $\times$ \\
\hline Etanercept & Interferon beta-1A & $\times$ & $\times$ & $x$ & $\times$ \\
\hline Everolimus & Raltegravir & $\times$ & $\times$ & $\times$ & $\times$ \\
\hline Ezogabine & Crizotinib & $\times$ & $\times$ & $\times$ & $\times$ \\
\hline Fentanyl (oral tablet) & Darifenacin & $\times$ & $\times$ & $x$ & $\times$ \\
\hline Fentanyl (oral transmucosal) & Furosemide & $\times$ & $\times$ & $\times$ & $x$ \\
\hline Fentanyl (transdermal) & Nitroglycerin & $\times$ & $x$ & $x$ & $x$ \\
\hline Formoterol (including formoterol, budesonide/formoterol) & Exenatide & $x$ & $\times$ & $x$ & \\
\hline Gemifloxacin & Rosuvastatin & $\times$ & $\times$ & $x$ & $\times$ \\
\hline Hydromorphone & Febuxostat & $\times$ & $\times$ & $x$ & $x$ \\
\hline Ketoconazole & Cimetidine & $\times$ & $\times$ & $x$ & $x$ \\
\hline Lapatinib & Pregabalin & $\times$ & $\times$ & $x$ & $x$ \\
\hline Leflunomide & Ursodiol & $\times$ & $x$ & $x$ & $x$ \\
\hline Lenalidomide & Lacosamide & $x$ & $x$ & $x$ & $x$ \\
\hline Levofloxacin (intravenous) & Palonosetron & $x$ & $x$ & $x$ & $x$ \\
\hline Levofloxacin (oral solution) & Posaconazole & $x$ & $x$ & $x$ & $x$ \\
\hline Levofloxacin (oral tablet) & Cinacalcet & $\times$ & $x$ & $\times$ & $x$ \\
\hline Mefloquine & Galantamine & $x$ & $x$ & $x$ & $x$ \\
\hline Methadone (oral solution) & Polyethylene Glycol & $\times$ & $\times$ & $\times$ & $x$ \\
\hline Methadone (oral tablet) & Sotalol & $\times$ & $\times$ & $\times$ & $\times$ \\
\hline Metoclopramide (intramuscular) & Ceftriaxone & $\times$ & $\times$ & $x$ & $x$ \\
\hline Metoclopramide (oral tablet) & Clarithromycin & $\times$ & $\times$ & $\times$ & $x$ \\
\hline Morphine & Omeprazole & $\times$ & $\times$ & $\times$ & $x$ \\
\hline Moxifloxacin (intravenous) & Palifermin & $\times$ & $\times$ & $x$ & $x$ \\
\hline
\end{tabular}




\section{APPENDIX B Black Box Warning Drugs and Controls (continued)}

\begin{tabular}{|c|c|c|c|c|c|}
\hline Active Pharmaceutical Ingredient Name & Control & $\begin{array}{c}\text { Brand vs. } \\
\text { Generic Match }\end{array}$ & $\begin{array}{c}\text { Small Molecule } \\
\text { vs. Biologic } \\
\text { Match }\end{array}$ & $\begin{array}{l}\text { CMS Protected } \\
\text { Class Match }\end{array}$ & $\begin{array}{c}\text { Formulation } \\
\text { Match }\end{array}$ \\
\hline Moxifloxacin (oral tablet) & Nebivolol & $x$ & $x$ & $x$ & $x$ \\
\hline Nevirapine & Lopinavir/ritonavir & $x$ & $x$ & $x$ & $x$ \\
\hline Norfloxacin & Almotriptan & $x$ & $x$ & $x$ & $x$ \\
\hline Ofloxacin & Acetazolimide & $x$ & $x$ & $x$ & $x$ \\
\hline Oxycodone & Simvastatin & $x$ & $x$ & $x$ & $x$ \\
\hline Oxymorphone & Terazosin & $x$ & $x$ & $x$ & $x$ \\
\hline Pomalidomide & Rilpivirine & $x$ & $x$ & $x$ & $x$ \\
\hline Propylthiouracil & Azithromycin & $x$ & $x$ & $x$ & $x$ \\
\hline Quetiapine & Darunavir & $x$ & $x$ & $x$ & $x$ \\
\hline Quinine sulfate & Silodosin & $x$ & $x$ & $x$ & $x$ \\
\hline Rituximab & Belimumab & $x$ & $x$ & & $\times$ \\
\hline $\begin{array}{l}\text { Rosiglitazone (including rosiglitazone, rosiglitazone/ } \\
\text { glimepiride, rosiglitazone/metformin) }\end{array}$ & Ranolazine & $x$ & $x$ & $x$ & $x$ \\
\hline Salmeterol (including salmeterol, fluticasone/salmeterol) & Methylnaltrexone & $x$ & $x$ & $x$ & \\
\hline Sunitinib & Etravirine & $x$ & $x$ & $x$ & $x$ \\
\hline Tapentadol & Saxagliptin & $x$ & $x$ & $x$ & $x$ \\
\hline Telaprevir & $\begin{array}{l}\text { Lanthanum } \\
\text { Carbonate }\end{array}$ & $x$ & $x$ & $x$ & $x$ \\
\hline Tenofovir (including tenofovir/emtricitabine) & Dasatinib & $x$ & $x$ & $x$ & $x$ \\
\hline Thiothixene & Ethosuximide & $x$ & $x$ & $x$ & $x$ \\
\hline Tigecycline & Anidulafungin & $x$ & $x$ & $x$ & $x$ \\
\hline Toremifene & Rufinamide & $x$ & $x$ & $x$ & $x$ \\
\hline Varenicline & Solifenacin & $x$ & $x$ & $x$ & $x$ \\
\hline
\end{tabular}

